\title{
THE DYNAMICS OF INTERTIDAL MUDFLATS AND SALTMARSHES WITHIN ESTUARIES
}

\author{
Townend, $\mathrm{I}^{1}$ Rossington, $\mathrm{K}^{1}$, Knaapen, $\mathrm{MAF}^{1}$, and Richardson, $\mathrm{S}^{1}$
}

\begin{abstract}
Whilst there has been extensive work on the study of the morphological response of estuaries, due to the transport of sediment under the forcing of waves and tides, and independent studies on the dynamics of saltmarsh, only recently have attempts been made to look at the interaction of the two. This paper furthers this endeavor by adding a simple saltmarsh model into the aggregated scale model of long-term morphology known as ASMITA. The results show the strong interaction between sediment availability within the estuary and marsh depth and, hence, the species that can be sustained. Under low rates of sediment loading the biology is the controlling influence, whereas under higher rates, typical of many UK estuaries, the sediment loading tends to be dominant. The importance of both the rate of sea level rise and the nodal tidal cycle are also explored.
\end{abstract}

Keywords :estuary, saltmarsh, geomorphology, dynamic equilibrium, sea level rise, lunar nodal tidal cycle

\section{INTRODUCTION}

There is a need to be able to predict the morphological development of estuaries over time scales of 10100 years in order to be able to make decisions on proposed developments and to develop policies in response to climate change. Various approaches to this problem are being developed (Huthnance et al. 2007) and here we focus on one of these. The ability to study the gross changes in estuary and tidal inlet volumes is explored using the aggregated modelling concept, ASMITA (Stive et al. 1998). This approach allows changes in the volume of model "elements" (eg large scale features delta, channel and tidal flats) to be examined in response to both external and internal perturbations. To-date this approach has been used to examine inlet response (Kragtwijk et al. 2004), sea level rise (van Goor et al. 2003) and the combined influence of sea level rise, changes in tidal range and the nodal tidal cycle (Townend et al. 2007).

Recent developments related to the eco-hydromorphology of saltmarshes has provided various formulations of the saltmarsh dynamics and their influence on the morphology, related to rates of inorganic settlement and biogenic production (Mudd et al. 2004; Morris, 2006; French, 2006; see also review of Townend et al. 2010). Here we make use of these developments to introduce a relatively simple saltmarsh representation as a new element within the ASMITA modelling framework to enable the study of the influence of saltmarsh on the estuary wide sediment dynamics.

This paper uses the extended ASMITA model to examine the response of an estuary to sea-level rise and to the nodal tidal cycle. The influence of the number of different species of marsh vegetation on the limiting rate of sea-level rise (maximum rate of sea-level rise where marsh vegetation can be sustained) is modelled, to relate resilience to sea-level rise to vegetation communities. In addition, changes to marsh community under the influence of the 18.6 year period nodal tidal cycle were modelled.

\section{MODEL DESCRIPTION}

\section{ASMITA}

ASMITA was first presented as a behaviour-based model "describing morphological interaction between a tidal lagoon or basin and its adjacent coastal environment" (Stive et al., 1998). The model consists of a schematisation of a tidal inlet system with the major morphological elements being viewed at an aggregated scale (e.g. Figure 1). The major assumption of ASMITA is that, under constant hydrodynamic forcing, each element tends towards a morphological equilibrium which can be defined as a function of hydrodynamic forcing and basin properties (van Goor et al., 2003). Empirical relationships are used to define the equilibrium volume of each element (Stive et al, 1998).

The morphological elements in ASMITA interact through sediment exchange. This interaction plays an important role in the morphological evolution of the whole system, as well as that of the individual elements (van Goor et al., 2003). Long-term, residual sediment exchange is assumed to occur between adjacent model elements and it is assumed that development of the tidal inlet does not affect the availability of sediment in the sea (van Goor et al., 2003).

\footnotetext{
${ }^{1}$ HR Wallingford Ltd, Howbery Park, Wallingford, Oxon, OX10 8BA, UK
} 


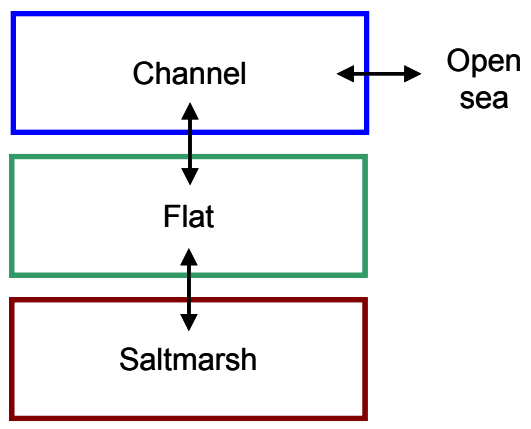

Figure 1 Three element ASMITA schematisation showing channel, flat and saltmarsh

When all model elements are in equilibrium, the sediment concentration throughout the whole system is equal to the sediment concentration in the surrounding sea, called the global equilibrium concentration $\left(\mathrm{C}_{E}\right)$. The sediment concentration in the sea is assumed to be unaffected by the evolution of the inlet and so the global equilibrium concentration is assumed to be constant (that is the long term average sediment concentration in the sea is assumed constant). Note, however, that while the concentration of the sea is assumed constant, this does not mean that there is a constant supply of sediment between the estuary and sea. The exchange between the estuary and the sea is governed by the differences in sediment concentration, which will change over time with evolution of the estuary and/or with changes in sediment supply to the nearshore zone.

Each element also has a local equilibrium concentration $\left(c_{e}\right)$, which refers to equilibrium from a perspective of local demand and is equal to the global equilibrium concentration when the element is in equilibrium (van Goor et al. 2003). The local equilibrium concentration indicates the extent to which the elements actual volume $(\mathrm{V})$ deviates from its equilibrium volume $\left(\mathrm{V}_{e}\right)$ and is given by equation 1.

$$
c_{e}=C_{E}\left(\frac{V}{V_{e}}\right)^{n_{i}}
$$

The difference between local equilibrium concentration $\left(c_{e}\right)$ and global equilibrium concentration $\left(C_{E}\right)$ represents the sediment demand of the element (van Goor 2001). When $c_{e}$ is larger than $C_{E}$ the element has a negative sediment demand and a tendency for erosion. When $c_{e}$ is smaller than $C_{E}$ the element has a positive sediment demand and a tendency towards accretion. The extent to which the sediment demand of an element is satisfied depends on sediment availability in the adjacent elements. Sediment availability is represented in ASMITA as the difference between an element's actual concentration $\left(c_{i}\right)$ and its local equilibrium concentration $\left(c_{e}\right)$. This difference drives volume changes within the elements (equation 2).

$$
\frac{d V}{d t}=S\left(w_{s}\left(c_{e}-c_{i}\right)+\frac{d \zeta}{d t}\right)
$$

Where $S$ is the element's surface area, $w_{s}$ is the vertical exchange coefficient for the element, $c_{i}$ is the element's actual concentration, $c_{e}$ is the local equilibrium concentration, $d \zeta / d t$ is the rate of relative sealevel rise.

When the element's local concentration $\left(c_{i}\right)$ is smaller than the local equilibrium concentration $\left(c_{e}\right)$, erosion will occur within the element; when the local concentration is larger than the local equilibrium concentration, sediment will accrete. Erosion and accretion within an element must be balanced by transfers of sediment across the element's boundaries, with adjacent elements or the outside world (equation 3).

$$
\sum \delta_{i, j}\left(c_{i}-c_{j}\right)=S_{i} w_{s i}\left(c_{i e}-c_{i}\right)
$$

Where $\delta_{i, j}$ is the horizontal exchange coefficient between the element and an adjacent element or the sea and $c_{j}$ is the concentration of the adjacent element. When describing exchanges with the outside 
world, the concentration in the adjacent element $\left(c_{j}\right)$ is replaced with the global equilibrium concentration $\left(C_{E}\right)$.

Sea-level rise creates additional sediment accommodation space by increasing the difference between an element's actual volume and its equilibrium volume. Dredging, land reclamation and realignment also increase the difference between an elements actual and equilibrium volumes, either by altering the actual volume, or if tidal prism is changed, by changing its equilibrium volume.

\section{Matrix formulation}

For a multi-element model the variables can be defined as either vectors or matrices, as proposed by Kragtwijk et al. (2004):

$\underline{V}$ element volumes

$\underline{S} \quad$ element surface areas

$\underline{c_{e}}$ local equilibrium concentrations

$\underline{c}$ element concentrations concentrations for fluxes into the system

$\underline{c_{\text {ext }}}$ from the environment

D horizontal exchange between elements

$\mathbf{Q}$ advective exchange between elements

B Expression to scale rate of change

$\underline{d}$ Expression for offset to rate of change $\underline{\delta_{e x t}}$ horizontal exchange coefficients with

$q_{\text {ext }}$ Advective flows into the system from the

$\underline{q_{\text {ext }}}$ environment concentration transport exponent. positive

$\underline{n}$ for wet volumes and negative for sediment volumes

$\underline{c_{b}}$ concentration of bed

\section{Diagonal matrices:}

W vertical exchange coefficient $w$

S surface areas

I unit or identity matrix

M unit matrix with sign of $\mathrm{n}$

The basic equations can now be written:

$$
\begin{aligned}
& \frac{d \underline{V}}{d t}=\frac{1}{c_{b}} \operatorname{MWS}\left(\underline{c_{e}}-\underline{c}\right) \\
& \left.\left(\mathbf{D}+\mathbf{Q}^{T}\right) \underline{c}=\mathbf{W S}\left(\underline{c_{e}}-\underline{c}\right)+c_{E} \underline{\left(\delta_{e x t}\right.}+\underline{k_{c}} \cdot \underline{q_{e x t}}\right) \\
& \underline{c_{e}}=c_{E} \underline{\gamma} ; \quad \underline{\gamma}=\left(\frac{\underline{V_{e}}}{\underline{V}}\right)^{\underline{n}} ; \quad \text { and } \quad \underline{k_{c}}=\frac{c_{e x t}}{/ c_{E}}
\end{aligned}
$$

The basis for calculating the change in volume due to some perturbation is then as follows:

$$
\frac{d \underline{V}}{d t}=\frac{1}{\underline{c_{b}}}(\mathbf{B} \underline{\gamma}-\underline{d})+\underline{\Delta V}
$$

where

$$
\begin{aligned}
& \mathbf{B}=c_{E} \operatorname{MWS}\left(\mathbf{I}-\left(\mathbf{D}+\mathbf{Q}^{T}+\mathbf{W S}\right)^{-1} \mathbf{W S}\right) \\
& \underline{d}=c_{E} \operatorname{MWS}\left(\mathbf{D}+\mathbf{Q}^{T}+\mathbf{W S}\right)^{-1}\left(\underline{\delta_{e x t}}+\underline{k_{c}} \cdot \underline{q_{e x t}}\right)
\end{aligned}
$$

The term $\underline{\Delta V}$ refers to any other changes in volume, introduced at any given time, within each element, e.g. for sea-level rise $\underline{\Delta V}=\underline{S} \frac{d \varsigma}{d t}$. 


\section{Saltmarsh model}

ASMITA has been extended to allow the inclusion of a saltmarsh element, taking due account of the biological contribution to sedimentation and the effect of sedimentation on biology (Knaapen et al. 2009). Sedimentation on saltmarsh areas is usually described as comprising an inorganic and an organic component, although the former is often broken down into a more detailed representation. For instance, the enhanced inorganic settling can be considered to be the result of modifying the flow conditions within the canopy, and trapping of the sediment by vegetation (Mudd et al. 2004).

In this study an equation for the change in marsh elevation as proposed by Morris et al. (2002) is used. The equation uses marsh depth, $D$, as a surrogate for the hydroperiod, with biomass production also defined as a function of marsh depth.

$$
\frac{d z}{d t}=\left(q_{m}+\Sigma(k \cdot B m)\right) \cdot D \quad \text { and } \quad B m_{i}=a_{i} D+b_{i} D^{2}+c_{i}
$$

Morris et al. define $q_{m}$ and $k$ as proportional to the rate of sediment loading and the efficiency of the vegetation as a sediment trap, although he notes that $k$ includes the influence of organic sedimentation. The biomass productivity, $B m$, is described for each species, $i$, by three coefficients $a, b$ and $c$. If the upper and lower limits of a species and the magnitude of the peak biomass are known, the values of the coefficients $a_{i}, b_{i}$ and $c_{i}$ can be determined using the right hand equation in (6). For a marsh in equilibrium, the rate of change of marsh elevation has to equal the long-term rate of change of sea level, $\zeta$. This leads to a cubic equation in $D$, where the smallest real positive root is the stable depth and the larger root is unstable against perturbations (Morris et al. 2002).

$$
\sum_{i} k_{i}\left[b_{i} D^{3}+a_{i} D^{2}+c_{i} D\right]+q_{m} D-\frac{d \zeta}{d t}=0
$$

The settling and trapping contributions are combined and treated as enhancements to the rate of vertical exchange $\left(w_{s}\right)$ and the organic sediment contribution is added to this. Consequently, $k$ is defined as the organogenic production, $k_{b m}$, and $q_{m}$ as the inorganic contribution to sedimentation based on an enhanced settling rate, $w_{s}$ ':

$$
\frac{d z}{d t}=w_{s}^{\prime} \cdot c+\sum_{i}\left(k_{b m} \cdot B m\right) \cdot D
$$

Here $w_{s}{ }^{\prime}=f\left(w_{s}, B m\right)$ is an enhanced vertical fall velocity that reflects the additional dissipation of the kinetic energy due to the vegetation and the influence of trapping (both of which depend on the size and density of the vegetation and hence are a function of biomass) and $c$ is the sediment concentration in the water column. The second term represents the organogenic contribution, where $k_{b m}$ is a rate coefficient. As outlined above the enhanced settling velocity can be posed as the combined influence of settling and trapping:

$$
\begin{array}{ll}
w_{s}^{\prime}=w_{s}+\alpha \cdot\left(\sum_{i} \frac{B m_{i}}{B m_{\max , i}}\right)^{\beta} \cdot D \text { when } c \leq c_{e} \\
w_{s}^{\prime}=w_{s} \quad \text { when } c>c_{e}
\end{array}
$$

where $B m_{\max , i}$ is the maximum biomass for the species and the coefficients $\alpha$ and $\beta$ scale the relative biomass to give the appropriate variation in enhanced settling rate. The condition relative to the local equilibrium concentration reflects the fact that enhanced settling will only take place when the element is importing sediment (ie accreting). 
Purich (2006) finds a very wide range of values for the efficiency of (artificial) vegetation in trapping sand (factors of hundreds). Moreover, there will be large variations over the seasons, which we don't resolve in ASMITA. This means that, with the data currently available, it is usually necessary to adopt typical values from the literature and then adjust the parameters to match the observed long-term change.

We now relate this to the rate equation used in ASMITA and note that the first term is similar to the form used to consider the rate of change of the water volume in an element:

$$
\frac{d V}{d t}=\left(w_{s}^{\prime} \cdot\left(c_{e}-c\right)-\sum_{i}\left(k_{b m} \cdot B m\right) \cdot D\right) \cdot S
$$

Note: the sign of the term $\Sigma\left(k_{b m} \cdot B m\right) \cdot D$ is taken to be negative as deposition of organic material to the bed will reduce the water volume, as does the first term when $c>c_{e}$.

Over the saltmarsh $V=D S$, so that we can write equation (8) as:

$$
\frac{d V}{d t}=w_{s}^{\prime} \cdot S \cdot\left(c_{e}-c\right)-\sum_{i}\left(k_{b m} \cdot B m\right) \cdot V
$$

where $c$ is the concentration and $c_{e}$ the local equilibrium concentration. Rather than use a relationship between volume and tidal prism, as used for channels and flats, equilibrium is based on the equilibrium depth for a given rate of sea level rise, equation (7), and the plan area of the marsh.

For the matrix formulation two additional variables are introduced: $\underline{k}_{b m}$ - rate of biomass production, and Bm - species biomass. This introduces an extra term into equation (5) for the rate of morphological change as follows:

$$
\frac{d \underline{V}}{d t}=\frac{1}{c_{b}}(\mathbf{B} \underline{\gamma}-\underline{d})-\mathbf{B m} k_{b m} \underline{V}+\underline{\Delta V}
$$

The term $\mathbf{B} \mathbf{m} k_{b m} \underline{V}$ only applies to saltmarsh elements and represents the additional settling due to enhanced settlement, trapping and biomass production.

\section{Application}

The ASMITA model was applied to examine the effect of vegetation characteristics on the limiting rate of sea-level rise and response to the nodal tidal cycle for the Humber Estuary, a large, macrotidal estuary on the east coast of the UK. A simple, three element schematisation, consisting of a channel, flat and saltmarsh element was used (Figure 1). Simulations were carried out with 0, 1, or 3 saltmarsh species. With no saltmarsh species, the saltmarsh element still exists as a separate element to the flat, but its behaviour is the same as for the flat. In this case it is referred to as the upper flat.

Saltmarsh in the Humber is dominated by Puccinellia maritima and Halimione portulacoides, with the lower marsh being comprised almost exclusively of Spartina anglica (Brown, 1998). Lower and upper species bounds were defined using depth factors related to the MHWN elevation, based on the species zonation work by Gray (1992). The depth is thus given by $d_{l i m}=a-$ depth_factor $z_{M H W N}$, where $a$ is the tidal amplitude. The peak biomass for the different species are based on the modelled peak biomasses used by Randerson (1979). The biogenic production rates are estimates bases on values cited in the literature (which are mainly for S. Alterniflora). For the Humber model, a MHWN of $1.6 \mathrm{mODN}$ was used with a tidal range of $5.84 \mathrm{~m}$, which leads to the parameter settings given in Table 1. 
Table 1 Saltmarsh properties used in model

\begin{tabular}{|l|c|c|c|c|c|c|}
\hline Species & $\begin{array}{c}\text { Min depth } \\
\text { factor }\end{array}$ & $\begin{array}{c}\text { Max depth } \\
\text { factor }\end{array}$ & $\begin{array}{c}\text { Min } \\
\text { depth } \\
(\mathrm{m})\end{array}$ & $\begin{array}{c}\text { Max } \\
\text { depth } \\
(\mathrm{m})\end{array}$ & $\begin{array}{c}\text { Max } \\
\text { biomass } \\
\left(\mathrm{kg} / \mathrm{m}^{2}\right)\end{array}$ & $\begin{array}{c}\text { Biogenic } \\
\text { production } \\
\text { rate }\left(k_{\text {bm }}\right) \\
\left(\mathrm{m}^{2} / \mathrm{kg} / \mathrm{yr}\right)\end{array}$ \\
\hline Spartina & 1.7 & 1.2 & 0.2 & 1.0 & 0.8 & 0.02 \\
Puccinellia & 1.9 & 1.5 & 0 & 0.52 & 1.5 & 0.002 \\
Halimione & 1.9 & 1.55 & -0.12 & 0.44 & 1.7 & 0.002 \\
\hline
\end{tabular}

In addition to the influence of sea level rise, tidal range is known to vary over an 18.6 year cycle known as the nodal tidal cycle. The nodal tide is believed to have a significant influence on intertidal morphology (Townend et al. 2007) and on saltmarsh behaviour (French, 2006). For the Humber this has an amplitude of approximately $0.16 \mathrm{~m}$.

\section{RESULTS}

To illustrate how the marsh varies under different conditions, the surface area was held constant at $3.72 \times 10^{7} \mathrm{~m}^{2}$. The variation in marsh volume is illustrated for various conditions in Figure 2. A marsh that is keeping pace with sea level should maintain an equilibrium depth. In Figure 2(a) this is seen to be the case when slr= $1.8 \mathrm{~mm}_{\mathrm{y}}{ }^{-1}$, for both of the values of global concentrations considered. However, with an increased rate of sea level rise of $6.0 \mathrm{~mm} \cdot \mathrm{y}^{-1}$, the marsh is less able to keep pace, particularly for the lower value of concentration. The prevailing depth of the marsh is also different in all four cases (see discussion below). The influence of the saltmarsh species is illustrated in Figure 2(b), again for a global equilibrium concentration, $\mathrm{c}_{\mathrm{E}}$, of $0.7 \mathrm{kgm}^{-3}$ and sea level rise of $1.8 \mathrm{~mm} . \mathrm{y}^{-1}$. The depth of marsh varies from $0.56 \mathrm{~m}$ with no species present, to $0.29 \mathrm{~m}$ with just Spartina present, and $0.06 \mathrm{~m}$ with all three species present (note: these are average marsh platform depths). Reducing $\mathrm{c}_{\mathrm{E}}$ to $0.07 \mathrm{kgm}^{-3}$ results in the marsh not keeping pace with sea level when there are no species present and settling at the deeper depth of $0.19 \mathrm{~m}$ with 3 species present.

The nodal cycle results in an oscillation about the sea level rise trend line. However, for 3 species and a very high marsh surface the depth over the marsh goes to zero and biological production almost ceases during the low periods of the nodal cycle, at least in terms of the annual average changes. Whilst this is probably exaggerating what really happens, field evidence for a cessation of accretion followed by periods of more rapid accretion have been reported (Morris et al. 2002, J. French; pers. comm. 2010).

(a)

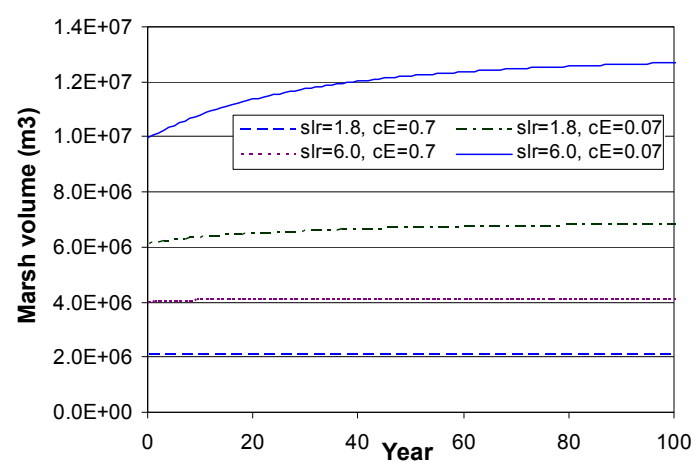

(b)

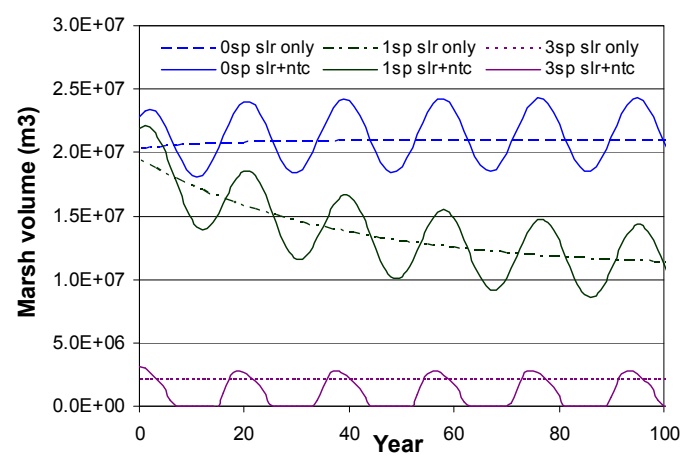

Figure 2 - Variation of marsh volume under different conditions (a) of sea level rise and sediment supply and (b) the number of marsh species present

Tidal range changes associated with the nodal tidal cycle generate relatively rapid changes in water depth over the marsh. French (2006) suggested that nodal tidal variations could account for changes in sedimentation rates on allochthonous marshes. The variation in the biomass of the individual species is illustrated in Figure 3 for the two global concentrations examined. With a rate of sea level rise of $1.8 \mathrm{~mm} . \mathrm{y}^{-1}$, and the deeper over marsh depth under the lower concentration, all three marsh species are 
present and make a contribution to the total biomass production. In contrast, the much higher platform under the higher concentration is unable to support the lower marsh Spartina species. The periods of very limited biomass production are also evident in Figure 3(b), although it is to be noted that there continues to be some production by Halimione because its zonation range extends above high water (see Table 1).

(a)

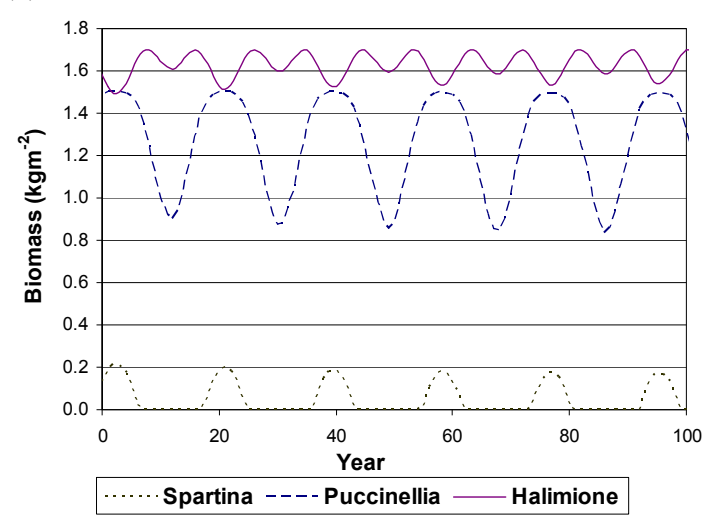

(b)

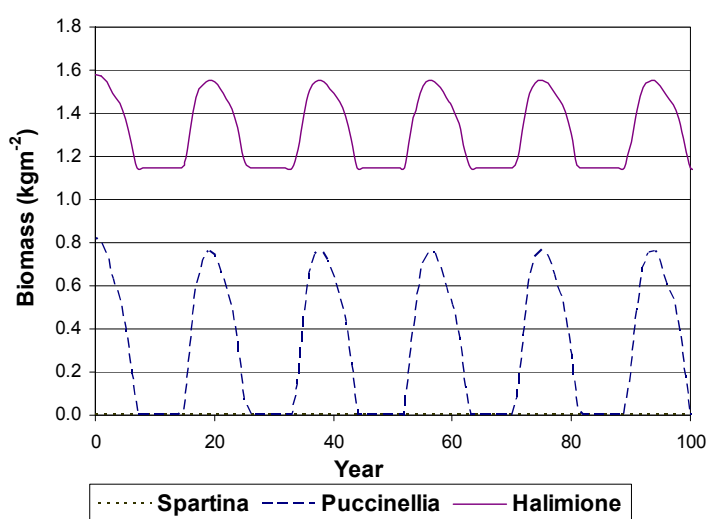

Figure 3 - Biomass of the individual species over time under the influence of sea level rise of $1.8 \mathrm{mmy}^{-1}$ and the nodal tidal cycle (a) for $C_{E}$ of $0.07 \mathrm{kgm}^{-3}$ and (b) for $C_{E}$ of $0.7 \mathrm{kgm}^{-3}$. Note that Spartina cannot be sustained under the high sediment loading case

\section{DISCUSSION}

The modelling results suggest that biological marsh characteristics, such as vegetation structure, are important in modifying the morphological response of saltmarshes to sea-level rise. The number of species coexisting on the marsh influences the limiting rate of sea-level rise that can occur before the marsh drowns. A single species of marsh vegetation is more resilient to sea-level rise than an unvegetated flat; two or more species add further resilience to sea-level rise.

The effect of introducing more species appears to be complex, and depends on the interaction between species: if multiple species can coexist they may increase the resilience to sea-level rise by increasing biomass and therefore sediment trapping and biological production. However, if adding more species gives a lower overall biomass, because the presence of more species makes the depth conditions less optimal for other species, then resilience to sea-level rise may be lowered. This will depend on the characteristics of the species present and their ability to thrive under the deeper conditions created by sea-level rise and the prevailing sediment loading.

The interaction of the rate of sea level rise and sediment loading merits further consideration. In their original paper, Morris et al. (2002) present the variation of equilibrium depth and biomass production as a function of the rate of sea level rise, Figure 4. They note that maximum biomass production gives rise to an optimal marsh depth, at a particular rate of sea level rise. For the range considered, a higher rate of sea level rise is unstable and a lower rate (typical of present day values) leads to sub-optimal productivity. This can be seen on Figure 4(a) where the rate of $6.0 \mathrm{~mm}^{-1} \mathrm{y}^{-1}$ leads to near optimal biomass production and an equilibrium depth of $0.26 \mathrm{~m}$. However, in this case there is not an immediate instability with increased rate of sea level rise and the instability does not occur until a rate of about $25 \mathrm{~mm} \cdot \mathrm{y}^{-1}$. This is because the global concentration is substantially higher than the values considered by Morris et al. and is having a much greater influence. Indeed this becomes the dominant influence for the higher sediment loading case, Figure 4(b). Here, although the biomass peaks at a rate of some $40 \mathrm{~mm} \cdot \mathrm{y}^{-1}$ and falls to zero at around $100 \mathrm{~mm} \cdot \mathrm{y}^{-1}$, the equilibrium depth continues to increase.

Considering equation (7), there are two limiting cases: 


$$
\begin{array}{cc}
q_{m}>>\sum k \cdot B m & q_{m} D \approx \frac{d \zeta}{d t} \\
q_{m}<<\sum k \cdot B m & \sum(k \cdot B m) D \approx \frac{d \zeta}{d t}
\end{array}
$$

The first case depends solely on the sediment loading and results in the sort of response shown in Figure 4(b). The second case is dependent on the biology and is more typical of the cases examined by Morris et al. (2002) and shown in figure 4(a).

(a)

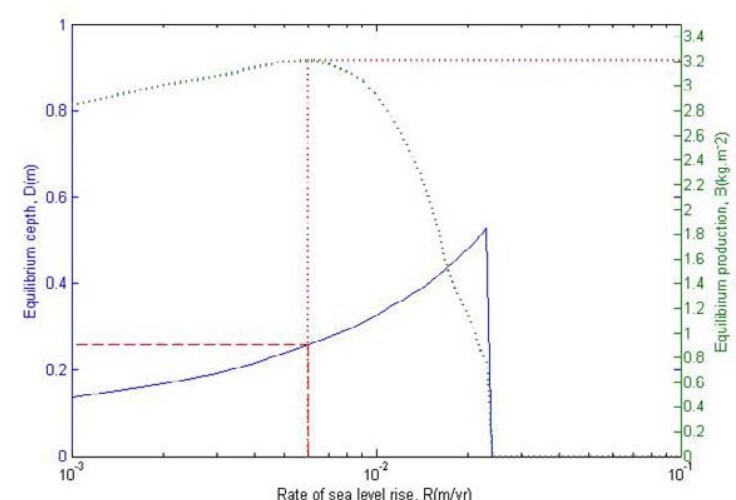

(b)

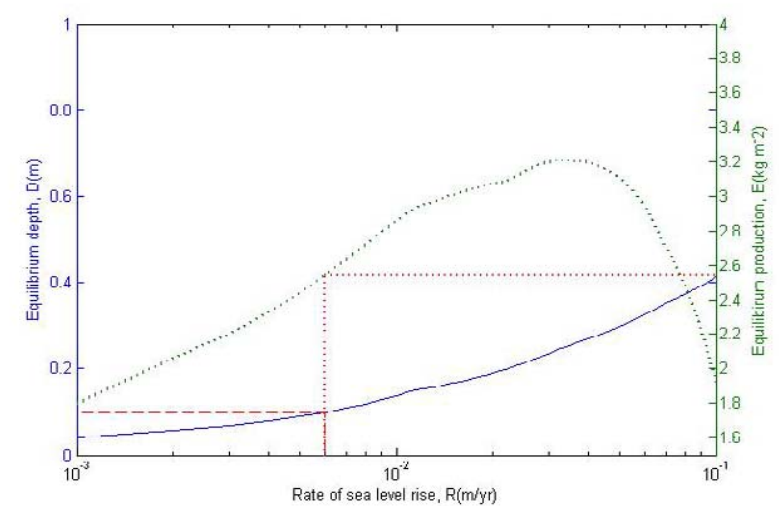

Figure 4 - Variation of equilibrium depth and biomass production as a function of the rate of sea level rise (a) for $C_{E}$ of $0.07 \mathrm{kgm}^{-3}$ and (b) for $C_{E}$ of $0.7 \mathrm{kgm}^{-3}$.

This variation in the dependence on sediment loading or biological production is illustrated in Figure 5, where the equilibrium depth is plotted as a function of both sediment loading and rate of sea level rise. The plot is for the biological settings defined in Table 1. Changing the values of $\mathrm{k}_{\mathrm{bm}}$ or the species definitions produces a different set of equilibrium depths but the pattern of the dependency on sediment loading and sea level rise remains broadly similar. This makes clear that for the range of sediment loadings considered by Morris et al. (0.0018 to $\left.0.00018 \mathrm{y}^{-1}\right)$, the equilibrium depths as a function of sea level rise are little changed and changing the biological parameters has a far greater effect. In contrast, for the sort of sediment loadings typical of many UK estuaries $\left(0.005\right.$ to $\left.0.05 \mathrm{y}^{-1}\right)$ there is a much stronger dependence on the sediment loading, to the point that at the upper end of the range it apparently dominates the equilibrium depth. 


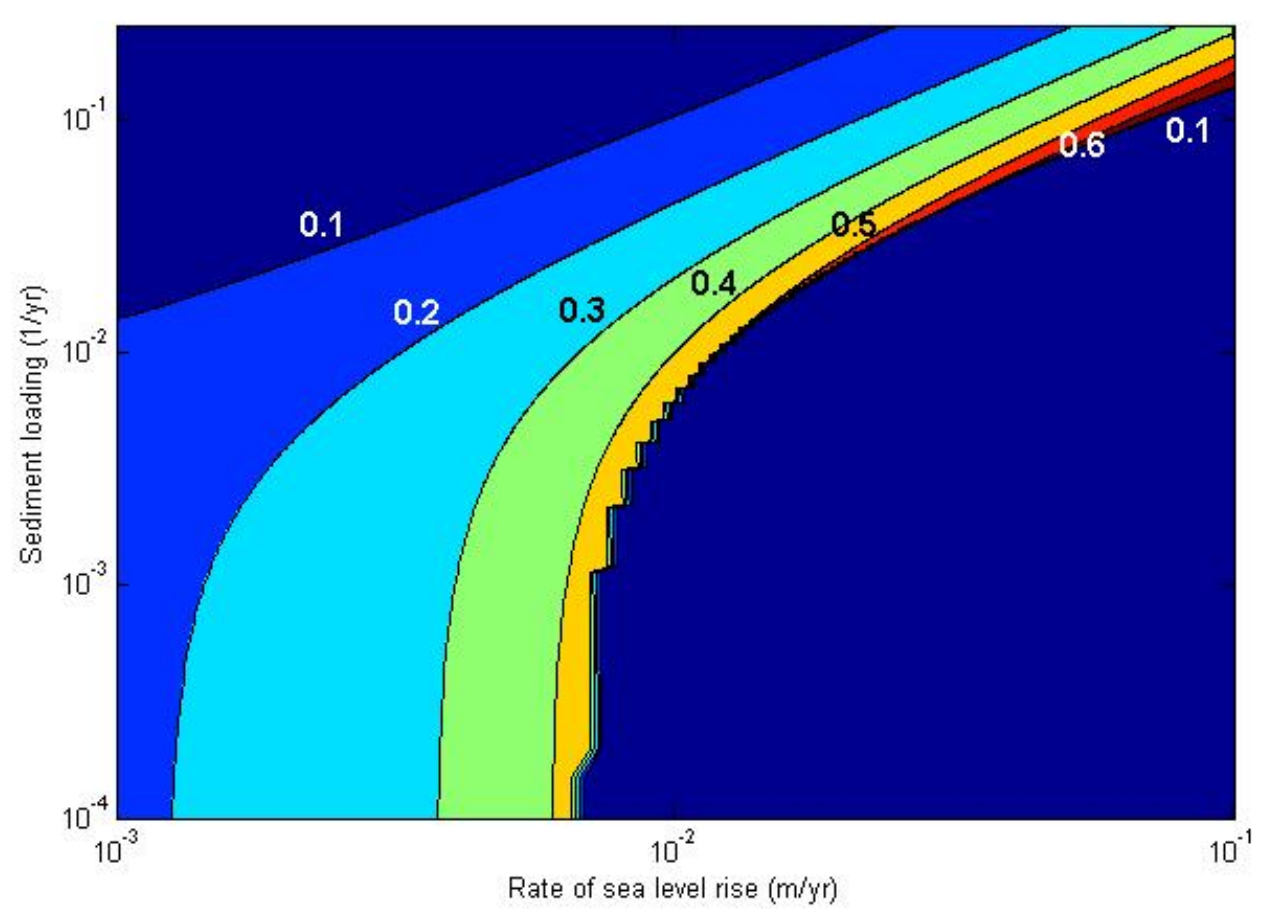

Figure 5 - Variation of equilibrium depth, based on equation 7 , as a function of sediment loading, $q_{m}$, and the rate of sea level rise (contours are in units of $m$ )

\section{CONCLUSIONS}

The morphological response of saltmarshes to sea-level rise is complex. The presence of vegetation enhances sedimentation on high intertidal area, allowing sediment surfaces to warp up with sea-level rise. With the presence of forcing signals such as the nodal tide, this implies a time dependent variation in marsh response and there is some limited field evidence to support this based on measurements in the US and UK (J. French, pers. comm.), although the records are too short to conclusively establish an association with the nodal tide.

Whether using the simple inter-species competition model of Morris et al., or more complex growthmortality species models (van de Koppel et al. 2005; Marani et al. 2007) it is clear that the 'state' of the marsh is very dependent on local conditions. This has been explored extensively for the case of Venice Lagoon (Amos et al. 2010). The results presented here show that sediment availability has a major influence but there is little field data available for such high sediment loading conditions. In order to develop this type of model further there is a need for some sustained monitoring programmes in a range of different environments (high/low sediment loading; sand/mud dominated; exposed/sheltered) to establish more robust phenomenological models of saltmarsh behaviour.

Finally, it is interesting to note the high sensitivity of marsh depth to the combination of sediment loading, rate of sea level rise and the marsh species present. This suggests that with better information on the marsh biology and elevations, coupled with information on the prevailing tidal conditions and the nodal cycle, it may be possible to use this information to better constrain the definition of the global equilibrium concentration used in ASMITA. The parameterization of the model has been explored by Wang et al. (2007), where they note the interdependence of the transport coefficient, n, and the global sediment concentration, $\mathrm{c}_{\mathrm{E}}$, in determining the morphological response time. This in conjunction with the horizontal and vertical rates of exchange determines the amplitude of the response under the nodal tidal signal. The additional and independent dependency of marsh depth, provides a means of further constraining the model set-up.

\section{REFERENCES}

Amos CL, Umgiesser G, Tosi L, Townend IH. 2010. The coastal morphodynamics of Venice lagoon, Italy: An introduction, Continental Shelf Research, 30(8), 837-846. 
Brown SL. 1998. Sedimentation on a Humber saltmarsh, In: Black KS, et al (Eds.), Sedimentary Processes in the Intertidal Zone, The Geological Society, London, pp. 69-84.

French JR. 2006. Tidal marsh sedimentation and resilience to environmental change: exploratory modelling of tidal, sea-level and sediment supply forcing in predominantly allochthonous systems., Marine Geology, 235, 119-136.

Gray AJ. 1992. Saltmarsh plant ecology: zonation and succession revisited, In: Allen JRL, Pye K (Eds.), Saltmarshes: Morphodynamics, conservation and engineering significance, Cambridge University Press, Cambridge, pp. 63-79.

Huthnance JM, Karynarathna G, Lane A, Manning A, Norton PA, Reeve DE, Spearman J, Soulsby RL, Townend IH, Wright AD. 2007. Development of estuary morphological models, In: Flood Risk Assessment II, Institute of Mathematics and its Applications, Southend on Sea, UK, pp. 131-140.

Knaapen MAF, Townend IH, Rossington SK, Fletcher CA, Spearman J. 2009. The dynamics of intertidal mudflat and salt marshes within estuaries, The Environmentalist, 84, 12-15.

Kragtwijk NG, Stive MJF, Wang ZB, Zitman TJ. 2004. Morphological response of tidal basins to human interventions, Coastal Engineering, 51, 207-221.

Marani M, D'Alpaos A, Lanzoni S, Carniello L, Rinaldo A. 2007. Biologically-controlled multiple equilibria for tidal landforms and the fate of Venice lagoon, Geophysical Research Letters, 34(L11402), 1-5.

Morris JT. 2006. Competition among marsh macrophytes by means of geomorphological displacement in the intertidal zone, Estuarine Coastal and Shelf Science, 69(3-4), 395-402.

Morris JT, Sundareshwar PV, Nietch CT, Kjerfve B, Cahoon D. 2002. Responses of coastal wetlands to rising sea level, Ecology, 83, 2869-2877.

Mudd SM, Fagherazzi S, Morris JT, Furbish DJ. 2004. Flow, sedimentation and biomass production of a vegetated salt marsh in South Carolina: toward a predictive model of marsh morphologic and ecologic evolution, In: Fagherazzi S, et al (Eds.), The ecogeomorphology of tidal marshes, American Geophysical Union, Washington DC, pp. 165-188.

Purich A. 2006. The capture of suspended particles by aquatic vegetation, University of Western Australia, 1-97.

Randerson PF. 1979. A simulation of saltmarsh development and plant ecology, In: Knights B, Phillips AJ (Eds.), Estuarine and coastal land reclamation and water storage, Saxon House, Farnborough, pp. 48-67.

Stive MJF, Capobianco M, Wang ZB, Ruol P, Buijsman MC. 1998. Morphodynamics of a tidal lagoon and adjacent coast, In: Physics of Estuaries and Coastal Seas: 8th International Biennial Conference on Physics of Estuaries and Coastal Seas, 1996, A A Balkema, Rotterdam, pp. 397407.

Townend IH, Fletcher CA, Knaapen MAF, Rossington SK. 2010. A review of saltmarsh dynamics, Water and Environment Journal, In press(doi: 10.1111/j.1747-6593.2010.00243.x), 1-12.

Townend IH, Wang ZB, Rees JG. 2007. Millennial to annual volume changes in the Humber Estuary, Proc.R.Soc.A, 463, 837-854.

van de Koppel J, van der Wal D, Bakker JP, Herman PMJ. 2005. Self-organisation and vegetation collapse in salt marsh ecosystems, The American Naturalist, 165(1), E1-12.

van Goor MA, Zitman TJ, Wang ZB, Stive MJF. 2003. Impact of sea-level rise on the morphological equilibrium state of tidal inlets, Marine Geology, 202, 211-227.

Wang ZB, de Vriend HJ, Stive MJF, Townend IH. 2007. On the parameter setting of semi-empirical long-term morphological models for estuaries and tidal lagoons, In: River, Coastal and Estuarine Morphodynamics, Taylor \& Francis, London, 1, pp. 103-111. 